\section{ECOLOGIA ORGANIZACIONAL: RELEVÂNCIA E IMPACTO NA PRODUÇÃO CIENTÍFICA NACIONAL E INTERNACIONAL}

\author{
ORGANIZATIONAL ECOLOGY: RELEVANCE AND \\ IMPACT IN NATIONAL AND INTERNATIONAL \\ SCIENTIFIC PRODUCTION
}

Erica Juvercina Sobrinho ericajuvercina@hotmail.com Doutoranda em Administração pela Universidade Federal de Uberlândia. Uberlândia - $M G$ - BR.

\section{Cintia Rodrigues}

cintia@ufu.br

Doutora em Administração. Professora da Universidade Federal de Uberlândia. Uberlândia $M G-B R$.

\section{RESUMO}

a) Objetivos do estudo: a perspectiva ecológica organizacional (HANNAN; FREEMAN, 1977) gerou grande excitação, controvérsia e debate dentro da comunidade científica dedicada à teoria das organizações e da administração (CLEMENTS; BAUM; CUMMING, 2016). Essa abordagem pode agregar valor, ao realizar uma análise profunda dos fenômenos ambientais, principalmente nas investigações que envolvem perspectivas futuras da organização. Diante disso, o objetivo do presente estudo é esboçar um panorama da produção científica acerca da ecologia organizacional de impacto nacional e internacional. b) Metodologia: realizou-se uma pesquisa bibliométrica por meio das bases de dados Web of Science e Scopus, que resultou em 856 artigos no período de 1958 a 2020. c) Principais resultados: os interesses e focos de investigação obtiveram relevante crescimento e destaque dessa teoria para o conhecimento científico. O mapeamento da produção apontou um cenário amplamente relacionado aos países economicamente desenvolvidos. Os artigos de origem nacional ainda apresentam baixa representatividade em comparação ao nível internacional. Foi evidenciado que os países economicamente desenvolvidos (Estados Unidos, Canadá, Países Baixos, Alemanha e Reino Unido) possuem maior interesse pela temática e, consequentemente, maior contribuição. d) Contribuições: primeiro, conectamos as literaturas relacionadas à ecologia organizacional de relevância tanto nacional como internacional. Segundo, fornecemos uma visão quantitativa da evolução da temática desde seu surgimento na literatura cujos indicadores resultantes apontam instituições, estudiosos e periódicos relevantes que aparecem na produção do conhecimento. Terceiro, fica evidenciado o potencial dessa teoria para fundamentar investigações diante das diretrizes fornecidas pela teoria, possibilitando, na prática, intervenções 
organizacionais como respostas planejadas às mudanças ambientais.

Palavras-chave: Ecologia Organizacional. Bibliometria. Nacional e Internacional.

\section{ABSTRACT}

a) Purpose: The organizational ecological perspective (HANNAN; FREEMAN, 1977) has generated great excitement, controversy, and debate within the scientific community devoted to organizations and management theory (CLEMENTS; BAUM; CUMMING, 2016). This approach can add value by conducting a thorough analysis of environmental phenomena, especially in investigations involving future perspectives of the organization. Given this, the aim of the present study is to outline an overview of the scientific production on organizational ecology of national and international impact. b) Methodology: To this end, a bibliometric research was carried out through the Web of Science and Scopus database, whose final sample resulted in 856 articles from 1958 to 2020. c) Findings: The interests and focuses of research obtained relevant growth and emphasis of this theory for scientific knowledge. The production mapping showed a scenario largely related to economically developed countries. The articles of national origin still have low representativeness in comparison to the international level. It was shown that economically developed countries (United States, Canada, the Netherlands, Germany and the United Kingdom) have greater interest in the subject and, consequently, greater contribution. d) Contributions: First, we connected the literature related to organizational ecology of national and international relevance. Second, we provide a quantitative view of the evolution of the theme since its emergence in the literature whose resulting indicators point to relevant institutions, scholars and journals that appear in the production of knowledge. Third, the potential of this theory is evidenced to support investigations in the face of the guidelines provided by the theory, allowing, in practice, organiza- tional interventions as planned responses to environmental changes.

Keyword: Organizational Ecology. Bibliometrics. National and International.

\section{INTRODUÇÃO}

O campo das teorias organizacionais abraça diferentes perspectivas axiológicas, ontológicas e epistemológicas, resultando em diferentes paradigmas de pesquisas que se articulam em um contexto inter e multidisciplinar. Assim, desde os primeiros estudos sobre organizações, questões relacionadas aos motivos e às condições em que as organizações emergem, persistem e se desenvolvem, continuam despertando o interesse de pesquisadores (VERHAAL; KHESSINA; DOBREV, 2015). Porém, essas teorias parecem padecer de certa ambiguidade em relação aos seus construtos e definições de termos específicos (FREITAS, 2000; SILVA; SANTOS; MACEDO, 2019), diante das constantes transformações ambientais.

No final da década de 1970, a maioria dos teóricos e gerentes das organizações modernistas tinha considerado a importância do ambiente para organização (HATCH; CUNLIFFE, 2006), tentando explicar como o ambiente opera. Nesse cenário, a publicação de Hannan e Freeman (1977) tornou-se o marco para os fundamentos da ecologia organizacional, gerando controvérsias e debates na comunidade científica dedicada à teoria das organizações e da administração (CLEMENTS; BAUM; CUMMING, 2016).

A teoria ecológica assume a dependência da organização com o ambiente. Seu papel é ajudar na compreensão das relações envolvendo uma organização, de forma a entender o que torna as organizações tão semelhantes entre si (DIMAGGIO; POWELL, 1983). Considerando que as organizações interagem continuamente com seu ambiente, a literatura tenta explicar como o ambiente institucional constitui o contexto social mais amplo para a ocorrência de processos ecológicos. A interação permite 
que as organizações façam todo tipo de atividades, como adquirir matérias-primas, contratar funcionários, garantir capital, vender produtos e serviços, obter conhecimento e construir, arrendar ou comprar instalações e equipamentos (HATCH; CUNLIFFE, 2006), bem como interagir com demais atores dessas trocas.

Considerando a importância de ampliar estudos que aprimorem o contexto ambiental organizacional (CLEMENTS; BAUM; CUMMING, 2016), a perspectiva ecológica pode agregar valor, realizando uma análise profunda dos fenômenos ambientais, principalmente nas investigações que envolvem perspectivas futuras da organização. Nesse sentido, a questão que orienta esta pesquisa foi assim formulada: Qual a relevância da produção científica sobre a Ecologia Organizacional? Para responder a essa questão, estabelecemos como objetivo levantar um panorama da produção científica sobre ecologia organizacional de impacto nacional e internacional.

Conhecer como essa temática está-se desenvolvendo de modo a avaliar qualitativamente a produção científica pode trazer contribuições para as pesquisas futuras no campo, bem como para a prática organizacional. As teorias organizacionais fornecem uma série de explicações aos profissionais responsáveis pelo desenvolvimento organizacional (SINGH; RAMDEO, 2020), orientando, inclusive, na tomada de decisões. Pautando-se na importância de conhecer e avaliar a produção sobre o tema, é necessário identificar pesquisadores e padrões no âmbito nacional e internacional, o que torna possível fornecer antecedentes suficientes para que os cientistas sociais realizem pesquisas relevantes (CARROLL; DOBREV; SWAMINATHAN, 2002).

Recentemente, os ecologistas começaram a dirigir maior atenção às transformações organizacionais (GANG, 2018; MAKAREVICH, 2018; MENDOZA-ABARCA; ANOKHIN; ZAMUDIO, 2015; SILVA; SANTOS; MACEDO, 2019), destacando fenômenos por meio de uma perspectiva ambiental. Numerosas análises sobre ajustes de forma ambiental são desenvolvidas, explicitando o vínculo entre forças sociais e organizacionais (CARROLL; DOBREV; SWAMINATHAN, 2002; HSU; HANNAN, 2005; SWAMINATHAN; WIEDENMAYER, 1991; TREMBLAY, 1993; VERHAAL; KHESSINA; DOBREV, 2015).

Tendências e distúrbios podem impactar a organização e sua interação com o ambiente, considerando-se o sistema de conexões globais. A pressão por organizações com identidades únicas (ÇAKMAKLI; BOONE; VAN WITTELOOSTUIJN, 2020), diante do empreendedorismo exacerbado (RATINHO et al., 2020), recai sobre a teoria da ecologia organizacional. Apesar de essa teoria ainda ser restrita no campo das pesquisas acadêmicas, sempre esteve presente na prática corporativa, empurrando novas decisões e práticas para superar barreiras como falência (KÜCHER; FELDBAUER-DURSTMÜLLER, 2019), escassez de recursos, necessidade de mudanças (ABBOTT; GREEN; KEOHANE, 2016; HANNAN; FREEMAN, 1984, p. 151) e intensificação da competição (LJUBOWNIKOW; ANG, 2020).

A perspectiva clássica da administração, em que vigora a busca da eficiência técnica da organização, tem dominado o debate acadêmico e a prática, no entanto, o desenvolvimento da ecologia organizacional, uma perspectiva evolucionária, oferece aos teóricos pressupostos desafiadores. A perspectiva ecológica desafia as abordagens tradicionais para a construção de uma teoria unidirecional (DOUGALL, 2005), voltada para a dinâmica evolutiva que influencia a diversidade organizacional. Diante disso, a complexidade ambiental enumera a variedade de situações e atividades com as quais as organizações devem interconectar-se ao longo do tempo e, ao mesmo tempo, compromete sua capacidade de se autogerenciar efetivamente (CLEMENTS; BAUM; CUMMING, 2016). Dessa forma, esta pesquisa justifica-se por concentrar-se na relevância da produção científica sobre essa perspectiva. 


\section{VERTENTES DA TEORIA ECO- LÓGICA ORGANIZACIONAL}

A abordagem ecológica explica a mudança organizacional, concentrando-se na distribuição dos recursos ambientais e nos termos em que estão disponibilizados (ALDRICH; WIEDENMAYER, 2019), de forma a estudar as interações entre organismos e seu ambiente, incluindo cooperação e competição. Os precursores da teoria ecológica (HANNAN; FREEMAN, 1977) afirmaram que as organizações individuais raramente conseguem mudanças radicais na estratégia e estrutura, diante das ameaças ambientais, justificando análises no nível de populações e não no nível da organização. Nessa perspectiva, é fundamental a sintonia entre as características organizacionais e um ambiente em transformação, o que favorece a sobrevivência institucional (VAN WITTELOOSTUIJN et al., 2018).

Os ecologistas trabalham em três níveis de análise: organização, população e comunidade (ALDRICH; WIEDENMAYER, 2019; CARROLL, 1984); entretanto, não há consenso quanto ao nível mais importante de análise (CARROLL, 1984). O nível organizacional envolve o estudo de eventos demográficos e os processos do ciclo de vida nas organizações individuais; a pesquisa no nível das populações concentra-se no crescimento e no declínio da população, bem como nas interações entre outras populações. No nível da comunidade, a análise focaliza no surgimento e no desaparecimento das organizações.

A teoria da ecologia populacional sustenta que a maior parte da variabilidade nas estruturas organizacionais ocorre por meio da criação de novas organizações e formas organizacionais e da substituição de antigas (FREEMAN; HANNAN, 1983; HANNAN; FREEMAN, 1977). Essa abordagem desafia a perspectiva contingencial, transformando-a numa teoria anti-management (CLEGG, 1996), pelo pressuposto de que o ambiente predomina sobre a organização. Diante de diversos fatores ambientais, é possível identificar o acaso orquestrando o desempenho organizacional (MACEDO; HERRMANN-PILLATH, 2019).
Há variantes dessa perspectiva que diferem amplamente em outras dimensões. A teoria de dependência de recursos enfatiza mudanças estruturais que neutralizam fontes de incerteza ambiental (CARROLL, 1985; CARROLL; SWAMINATHAN, 2011; HANNAN et al., 1995). A ecologia populacional assume o considerável poder do ambiente sobre a organização, assim como a teoria da dependência de recursos.

No entanto, enquanto a teoria da dependência de recursos está enraizada na análise no nível organizacional, a ecologia populacional concentra a maior parte de sua atenção no meio ambiente. O que interessa aos ecologistas da população não é como uma organização obtém sua própria sobrevivência por meio da competição por recursos escassos e recursos críticos (como na teoria da dependência de recursos), mas os padrões de sucesso e fracasso entre todas as organizações que competem em um dado conjunto de recursos (HATCH; CUNLIFFE, 2006). É o caso do setor de bancas de jornais, em que a sobrevivência é questionada diante de produtos substitutos que induzem a mudança no consumo (SILVA; FIGUEIREDO; SANTOS, 2015).

Uma versão institucionalmente orientada dessa perspectiva sustenta que as estruturas organizacionais são racionalmente adaptadas aos modos de organização predominantes e endossados normativamente (DIMAGGIO; POWELL, 1983; MEYER; ROWAN, 1977). Os critérios de seleção são definidos por meio da operação de forças de mercado, pressões competitivas, lógica da estruturação organizacional interna, conformidade com normas institucionalizadas e outras forças (ALDRICH; WIEDENMAYER, 2019; HANNAN; FREEMAN, 1977), fatores que explicam, em grande parte, a mortalidade corporativa (KÜCHER et al., 2020) e a necessidade contínua de modificar estrutura e processos internos (SILVA; SANTOS; MACEDO, 2019).

Uma população com necessidades de recursos semelhantes compete mais intensamente, o que é explicado pela perspectiva de concorrência interorganizacional baseada na densidade populacional (BARNETT; CARROLL, 1987; 
BAUM; MEZIAS, 1992; SWAMINATHAN; WIEDENMAYER, 1991), que é o número de organizações existente em uma população (VAN WITTELOOSTUIJN et al., 2018). O crescimento da densidade leva à legitimação ("valor social dado como garantido") (HANNAN et al., 1995, p. 510) até certo limite. Isso porque, pela perspectiva institucional, as organizações dependem da aceitação da sociedade em que operam (HATCH; CUNLIFFE, 2006). Especificamente, à medida que a densidade sobe de zero para um nível alto (não especificado), as taxas de fundação aumentam inicialmente e depois caem, e as taxas de mortalidade diminuem inicialmente e depois aumentam (HANNAN et al., 1995; KÜCHER; FELDBAUER-DURSTMÜLLER, 2019). Assim, a sinalização social é fundamental na evolução contínua das organizações (POSTHUMA et al., 2018).

A teoria ecológica sustenta que, sob certas condições ambientais e organizacionais, o aumento do domínio de grandes empresas em um setor aumentará as chances de vida de organizações especializadas (CARROLL; DOBREV; SWAMINATHAN, 2002; TSAI; MACMILLAN; LOW, 1991). Como consequência, as variações ambientais induzem à mortalidade de instituições generalistas, em prol das especialistas: é o nicho populacional (FREEMAN; HANNAN, 1983; MAKAREVICH, 2018); por exemplo, a governança internacional de energias renováveis (OVERLAND; REISCHL, 2018), tentando se impor em face das companhias petroleiras.

Os ecólogos têm destacado a perspectiva da inércia estrutural, que é a influência dos fatores ambientais e das organizacionais nas taxas de mudanças em organizações individuais e a adaptabilidade dos diferentes tipos de mudanças. Nesse sentido, a perspectiva da adaptação estratégica explica que, embora os gerentes desenvolvam e implementem estratégias, estas não determinam diretamente o sucesso organizacional (TREMBLAY, 1993; TSAI; MACMILLAN; LOW, 1991). Em vez disso, elas são uma das muitas fontes de variação aleatória que serão selecionadas a favor ou contra o am- biente. Há evidências direcionando os conflitos organizacionais causados por barreiras de recursos e barreiras informacionais (REN et al., 2017). O aprendizado é adaptável e impacta na organização, ajustando melhor ao seu ambiente; outras vezes, o aprendizado não é adaptável, e a adaptação da organização ao ambiente não é aprimorada (GREVE; ARGOTE, 2015).

No Brasil, as investigações destacaram a aplicabilidade da adaptação organizacional ao ambiente (GUERRAZZI; SERRA, 2017; SILVA; SANTOS; MACEDO, 2019), outras aprofundaram em questionamentos da perspectiva ambiental (CUNHA, 1999; MARQUESAN; FIGUEIREDO, 2018). Na literatura internacional, percorre as vertentes desse campo teórico, como as pressões ambientais na sobrevivência de uma organização subsidiária de multinacional (PENG; BEAMISH, 2019); a competição populacional, em que o primeiro a chegar limita os demais (MORIN, 2020); a idade organizacional afeta, negativamente, a velocidade da mudança exigida pelo ambiente (LE MENS; HANNAN; PÓLOS, 2015); a perpetuidade de uma empresa familiar (POWERS; ZHAO, 2019); e os impactos da especialização organizacional baseada em uma franquia cervejeira (BECK et al., 2019). A literatura também apresenta uma aplicabilidade diversificada, como o estudo do setor espacial e as possíveis evoluções no comércio espacial (DENIS et al., 2020), as mudanças na demanda por cannabis pela interação da organização com os clientes (HSU; KOVÁCS; KOÇAK, 2019); a sobrevivência organizacional de agências públicas explicada pela densidade (VAN WITTELOOSTUIJN et al., 2018); e a tendência ao aumento da burocracia organizacional como resposta, em diferentes níveis, às regras externas à organização, ou seja, é resposta à pressão do meio ambiente (KAUFMANN; VAN WITTELOOSTUIJN, 2018).

As fronteiras tradicionais entre as teorias estão ficando cada vez mais embaçadas, à medida que cada teoria organizacional aborda novas questões (GREVE; ARGOTE, 2015). A construção de pontes entre a teoria organizacional e o campo social impulsionou novos mode- 
los para a teoria organizacional contemporânea (FREEMAN; HANNAN, 2014). Nas últimas décadas, os estudos organizacionais utilizam cada vez mais múltiplas perspectivas: indivíduo, grupo ou subunidade organizacional, organização, setor ou população organizacional e campo (HAVEMAN; WETTS, 2019). Abordagens da administração com raízes sociológicas possibilitam combinar dimensões, definindo setores corporativos e padrões de uso e consumo (MACEDO; HERRMANN-PILLATH, 2019). Paralelamente, a ecologia organizacional ainda pode ser combinada com outras teorias em busca de um equilíbrio em seu poder explicativo (LANDER; HEUGENS, 2017). Esse desenvolvimento parece direcionar para novos mecanismos de aprendizagem organizacional e novos interesses empíricos.

Dada a importância das organizações para a sociedade, é relevante aprofundar no campo da ecologia organizacional, visto que a inter-relação entre o ambiente dos negócios e o campo social é capaz de definir o futuro corporativo. Quando essas relações são explicitadas, a mudança organizacional torna-se elemento-chave para o desenvolvimento do paradigma ecológico. Esse processo é crucial para empreendedores e pesquisadores que tentam entender o reflexo das características organizacionais ao longo do tempo (DELMAR; SHANE, 2004). Diante disso, uma análise da produção científica voltada para a ecologia organizacional é importante para apontar oportunidades e lacunas na literatura que possam contribuir para a compreensão das anomalias ambientais na diversidade organizacional.

\section{PROCEDIMENTOS METODOLÓ- GICOS}

Este estudo foi conduzido por uma pesquisa do tipo bibliométrica, que vem sendo utilizada em diversas áreas do conhecimento para aprofundar análises no âmbito científico (HOLGADO-SILVA et al., 2018). Além disso, esse tipo de pesquisa possibilita identificar grupos e áreas de excelência acadêmica de determinado tema (SOUZA, 2013).
O foco dessa metodologia está em quantificar as produções por meio de um filtro nos termos em comum, mas não se concentra em analisar o conteúdo dos estudos (DAIM et al., 2008). Com a utilização de técnicas e tecnologias informacionais, a bibliometria permite compreender, de forma contextualizada, as produções científicas, seja pela autoria, nacionalidade, instituição, seja por outros (HOLGADO-SILVA et al., 2018).

Esta pesquisa contituiu-se das seguintes etapas: busca de artigos nas bases, análise descritiva, análise de autoria e país de origem, nível de impacto, palavras-chave e termos base. O termo principal pesquisado foi "Ecologia Organizacional" e sua versão em inglês, "Ecology Organizational", nas bases indexadoras de estudos empíricos Scopus (da Elsevier) e Web of Science (da Thomson Reuters), conforme métrica aplicada em estudos anteriores (HOLGADO-SILVA et al., 2018). As duas bases de dados são ferramentas robustas para medir a ciência no nível macro (ARCHAMBAULT et al., 2009). A busca considerou artigos nos idiomas inglês e português, indexados nas bases mencionadas de modo a possibilitar a comparação da relevância do tema em âmbito internacional e nacional. Como resultado da busca, obteve-se uma base de 449 observações pela base Scopus e 407 na Web of Science, totalizando 856 artigos entre os anos de 1958 a 2020. Com a exclusão dos estudos duplicados, a amostra finalizou com 604 observações.

As bases selecionadas correspondem a sistemas de indexação, pesquisa e disponibilização de produção científica, particularmente, das áreas de Administração de Empresas, Contabilidade e Turismo, conforme classificação do Qualis CAPES e fator de impacto Scimago. Por proporcionar significativo acervo de elevado impacto científico, tais bases se tornaram referência aos estudiosos do assunto.

Para além da análise dos dados indexados na Web of Science, optou-se por acrescentar a análise dos dados indexados na Scopus, procedendo-se à comparação dos resultados entre ambas as bases de dados sempre que adequado e possível, assim como Boavida, Rodrigues e Saraiva (2015). Utilizou-se o software R para análise dos dados, 
por meio da ferramenta de bibliometria. Os resultados são apresentados na seção seguinte.

\section{RESULTADOS E DISCUSSÃO}

Os resultados da pesquisa evidenciaram as principais características da produção científica relacionadas com os termos "Ecologia Organizacional" e "Organizational Ecology", nos indexadores Web of Science e Scopus, no período entre 1958 e 2020 . Na tabela 1, apresenta-se uma análise descritiva dos dados coletados. Apesar de a base Scopus apresentar período temporal bem menor, possui maior número de publicações $(52,4 \%)$. Além disso, observa-se que o Scopus é a base mais procurada por autores do tema analisado (959). Fica evidenciado que as principais publicações referem-se a artigos científicos, seguido por livros (ou parte deles). Apesar de o marco teórico ser considerado em 1977, com o estudo de Hannan e Freeman, outros estudiosos já haviam lançado lampejos sobre a interação organizacional com o ambiente, sendo, portanto, estudos base, o que explica estudos de períodos anteriores. Um exemplo disso é o estudo de Gibbs e Martin (1958), intitulado "Urbanization and Natural Resources: a study in organizational ecology".

Tabela 1 - Descritiva com principais informações da amostra

\begin{tabular}{|c|c|c|c|}
\hline Main Information & Scopus & Web of Science & Total \\
\hline Documents & 449 & 407 & 604 \\
\hline Sources (Journals, Books, etc.) & 283 & 227 & 280 \\
\hline Keywords Plus (ID) & 994 & 876 & 788 \\
\hline Author's Keywords (DE) & 985 & 802 & 902 \\
\hline Period & $1972-2020$ & $1958-2019$ & $1958-2020$ \\
\hline Average citations per documents & 29.54 & 34.11 & 32.46 \\
\hline Authors & 740 & 653 & 740 \\
\hline Author Appearances & 959 & 864 & 959 \\
\hline Authors of single-authored documents & 132 & 120 & 127 \\
\hline Authors of multi-authored documents & 608 & 533 & 588 \\
\hline Single-authored documents & 153 & 144 & 151 \\
\hline Documents per Author & 0.607 & 0.623 & 0.601 \\
\hline Authors per Document & 1.65 & 1.6 & 1.6 \\
\hline Co-Authors per Documents & 2.14 & 2.12 & 2.13 \\
\hline Collaboration Index & 2.05 & 2.03 & 2.03 \\
\hline \multicolumn{4}{|l|}{ Document types } \\
\hline Article & 327 & 311 & 475 \\
\hline Article in press & 5 & 25 & 28 \\
\hline Book & 5 & 2 & 5 \\
\hline Book chapter & 24 & 16 & 24 \\
\hline Conference paper & 44 & 11 & 37 \\
\hline Editorial & 1 & 6 & 6 \\
\hline Note & 2 & 2 & 3 \\
\hline Retracted & 1 & 2 & 1 \\
\hline Review & 40 & 32 & 25 \\
\hline
\end{tabular}

Fonte: elaborado pelos autores, gerado por Bibliometrix R Studio. 
Ainda na tabela 1, a média de citações por documento foi maior pelo Web of Science $(34,11)$. Ao considerar o total de estudos, com a exclusão de duplicidades encontradas, é possível identificar que o formato de artigo tende a aparecer nas duas bases utilizadas. Isso pode contribuir com pesquisadores que possuem restrições de acesso a alguma base. Conforme gráfico 1, considerando a quantidade de produção constante nas bases, observa-se que a década de 1990 e os anos 2000 apresentam robustez com citações realizadas em estudos envolvendo o tema. É um indicativo do ápice de investigações, diante do maior interesse de pesquisadores por realizar citações em novos estudos organizacionais.

Gráfico 1 - Quantidade de citações por ano das bases Scopus e Web of Science

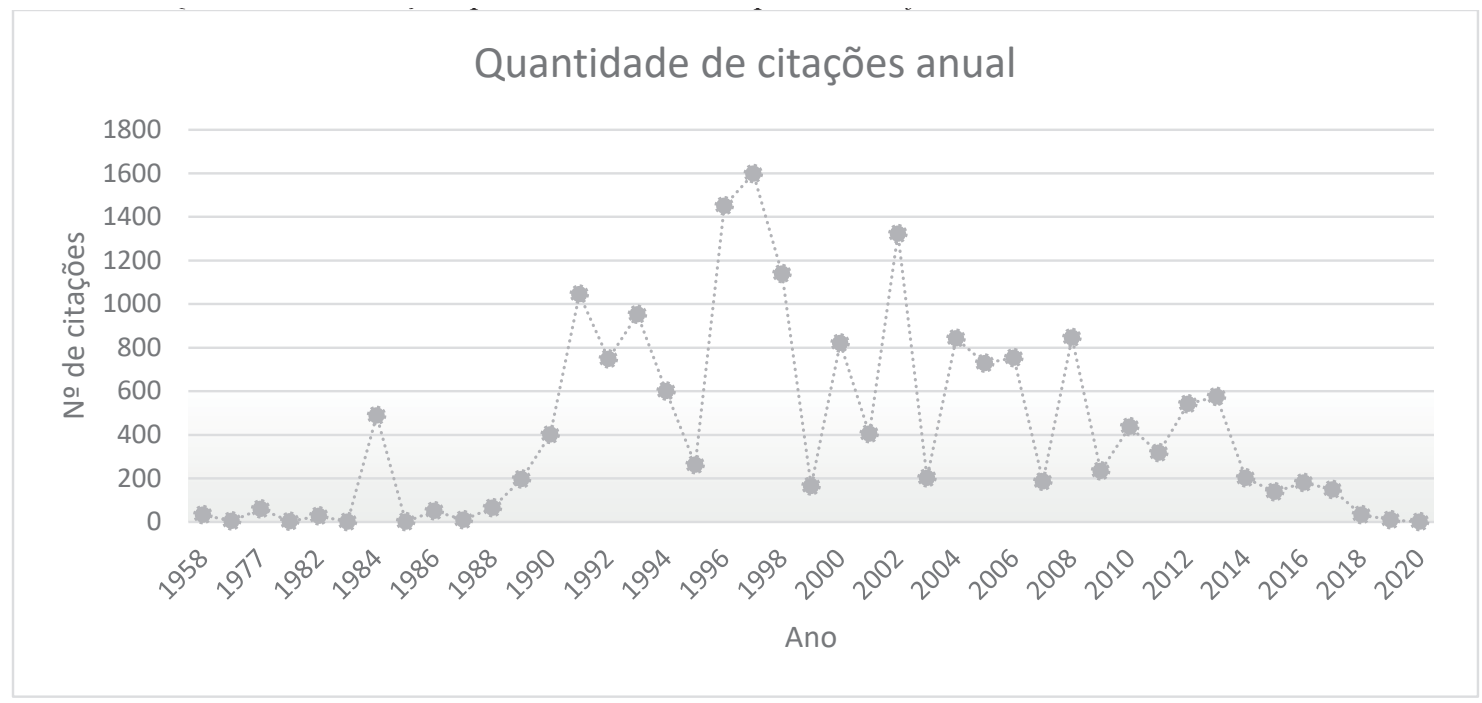

Fonte: elaborado pelos autores, gerado por Bibliometrix R Studio.

No gráfico 2, tem-se a análise da produção anual relacionada à abordagem da Ecologia Organizacional. Como a década de 1970 corresponde ao surgimento do estudo de maior impacto sobre o assunto, é natural que a linha do tempo seja insignificante no período anterior. A visão orientada para as ciências sociais ganhou importância substancial a partir dos anos de 1990 (KÜCHER; FELDBAUER-DURSTMÜLLER， 2019), especialmente, com o empreendedorismo desempenhando papel fundamental no desenvolvimento de outros formatos organizacionais (SINGH; LUMSDEN, 1990).
Os resultados apontam que houve uma ampliação das pesquisas envolvendo o tema a partir dos anos 2000, considerando maior interesse da academia em compreender a relação organização-ambiente. Apesar do aumento na produção acadêmica, seu impacto ainda é limitado pela falta de influência sobre estudiosos fora de sua órbita (AL-TURK; ALDRICH, 2019), determinando uma comunidade acadêmica relativamente exclusiva. Isso também pode explicar a queda relevante no ano de 2018 em estudos relacionados ao tema, apesar de sua ascensão nos últimos anos. 
Gráfico 2 - Produção científica anual das bases Scopus e Web of Science

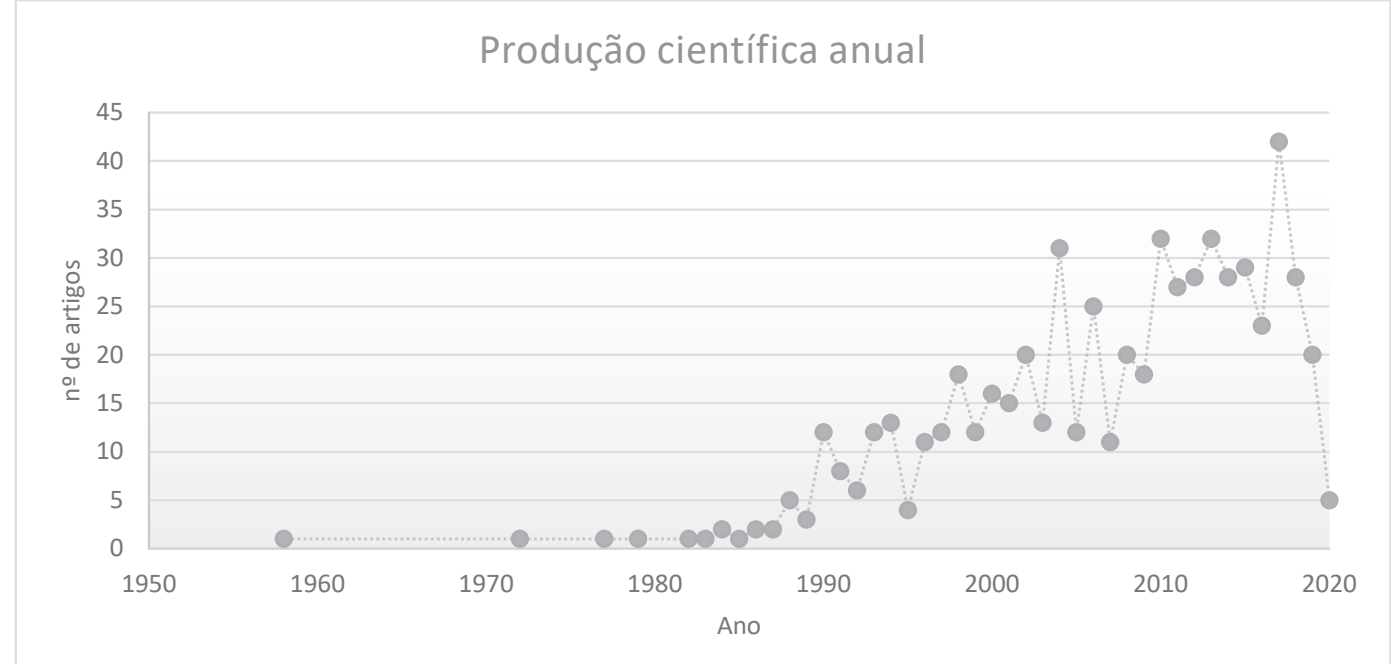

Fonte: elaborado pelos autores, gerado por Bibliometrix R Studio.

Com relação à autoria, o gráfico 3 apresenta os autores com maior relevância. Van Witteloostuijn aparece nas bases analisadas como um dos principais autores sobre o tema, possuindo 28 estudos publicados ao longo do período analisado, seguido por Carroll com 25 estudos. Outros autores também apresentam quantitativo de estudos relevante para Ecologia Organizacional, como Boone com 15 estudos, Barnett com 14 estudos, Hannan com 12 estudos, Swaminathan e Dobrev com 10 estudos e Peli com 8 estudos. O destaque fica para a condição dos periódicos que, por vezes, utilizam mais de indexador e, por isso, os estudos são encontrados tanto na Scopus como na Web of Science.

Gráfico 3 - Autores mais relevantes das bases Scopus e Webof Science

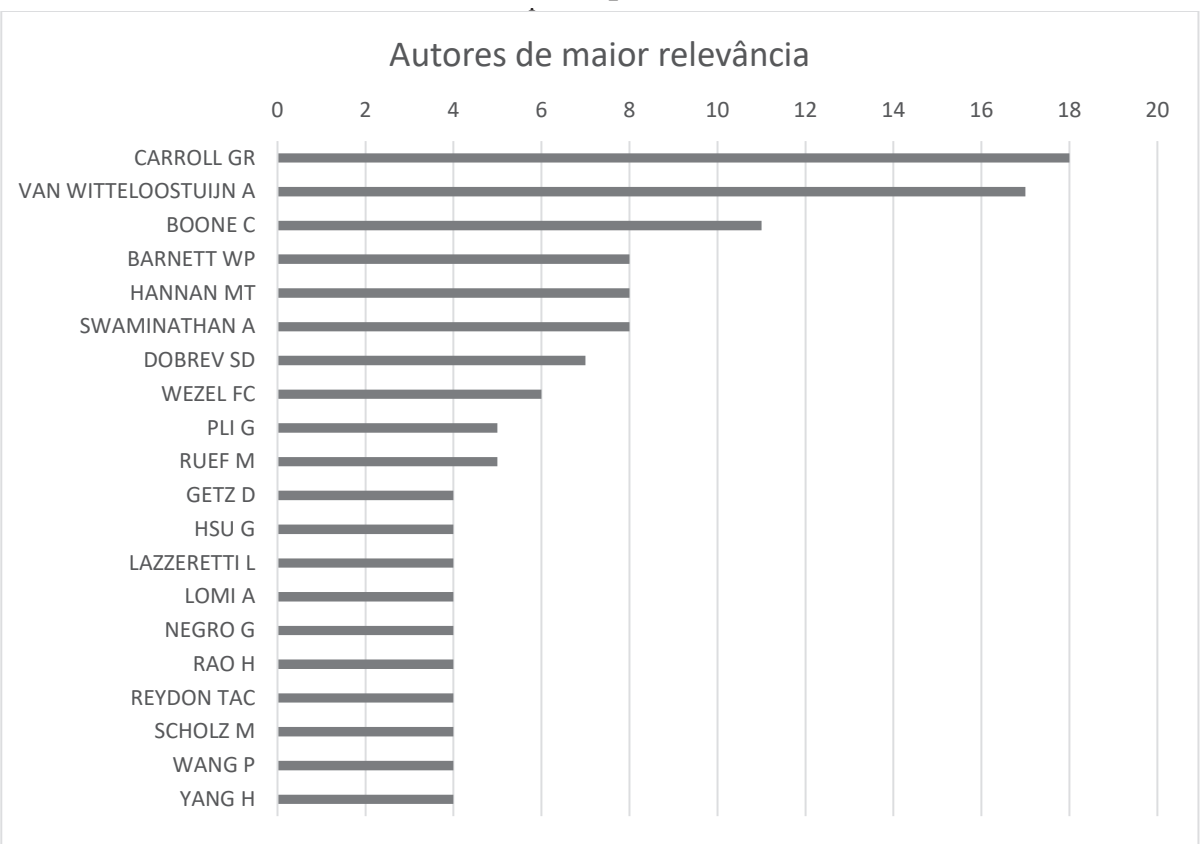

Fonte: elaborado pelos autores, gerado por Bibliometrix R Studio 
Ao considerar o fator de impacto, o gráfico 4 destaca o autor Glenn R. Carroll (University of California) com maior relevância nos trabalhos nas duas bases consideradas neste estudo. Ele é professor de sociologia e estuda o comportamento organizacional e a autenticidade socialmente construída, com questões sobre organizações, gerenciamento estratégico e evolução industrial. Aqui fica evidenciada a importância desse autor, apesar de Arjen Van Witteloostuijn (University of Groningen) apresentar maior número de publicações, o impacto de suas análises é menor. Este último possui formação em administração e estuda o comportamento e a estrutura das organizações, abordando sucesso e fracasso organizacional. O destaque é para o autor Stanislav Dobrev (University of Stanford) que aparece em $7^{\circ}$ lu- gar na quantidade de submissões e equipara-se a Arjen Van Witteloostuijn no impacto das pesquisas. Dessa forma, esses autores aparecem com maior frequência em algum artigo, possivelmente com análises inovadoras.

A metodologia do cálculo de fator de impacto pode comprometer a análise, visto que pode ocorrer autocitação e citação cruzada. Conforme Wallin (2005) ' citações a publicações do mesmo autor ou a grupos de autores se referenciarem é comum e pode comprometer uma análise bibliométrica por ser de difícil identificação nas metodologias utilizadas, exigindo parâmetros não abordados no presente estudo. Apesar disso, ainda é a referência mundialmente utilizada no campo científico (BIENERT et al., 2015) para medir o grau de qualidade do estudo.

Gráfico 4 - Autores com produção de maior impacto das bases Scopus e Web of Science

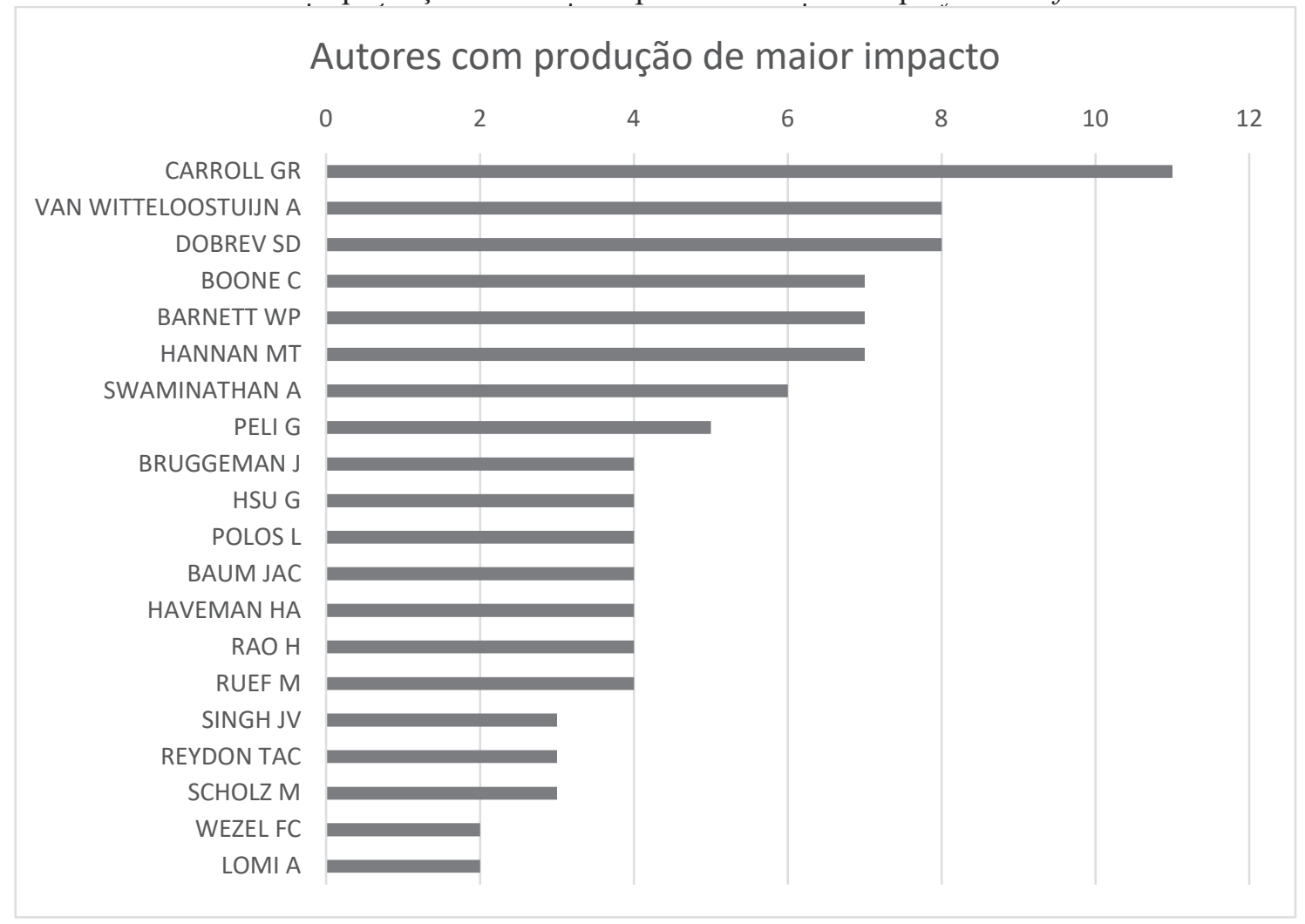

Fonte: elaborado pelos autores, gerado por Bibliometrix R Studio. 
O gráfico 5 relaciona a preferência de periódicos científicos para submissão de estudos envolvendo Ecologia Organizacional, destacando os três primeiros com fator de impacto 14. A Revista Organization Studies é um periódico multidisplinar tanto para análises teóricas como práticas no âmbito organizacional com raízes nas ciências sociais. O Journal Strategic Management é um periódico direcionado para estudiosos em gestão estratégica, tanto para aprimoramento teórico quanto para explorar fenômenos organizacionais. A Revista Organizational Science é amplamente reconhecida na área de comportamento, gerenciamento e teoria organizacional, enquanto a Administrative Science Quarterly promove a administração em sentido amplo para incluir os processos de criação, coordenação e transformação do ambiente social.

Gráfico 5 - Periódicos de maior impacto das bases Scopus e Web of Science

Periódicos de maior impacto

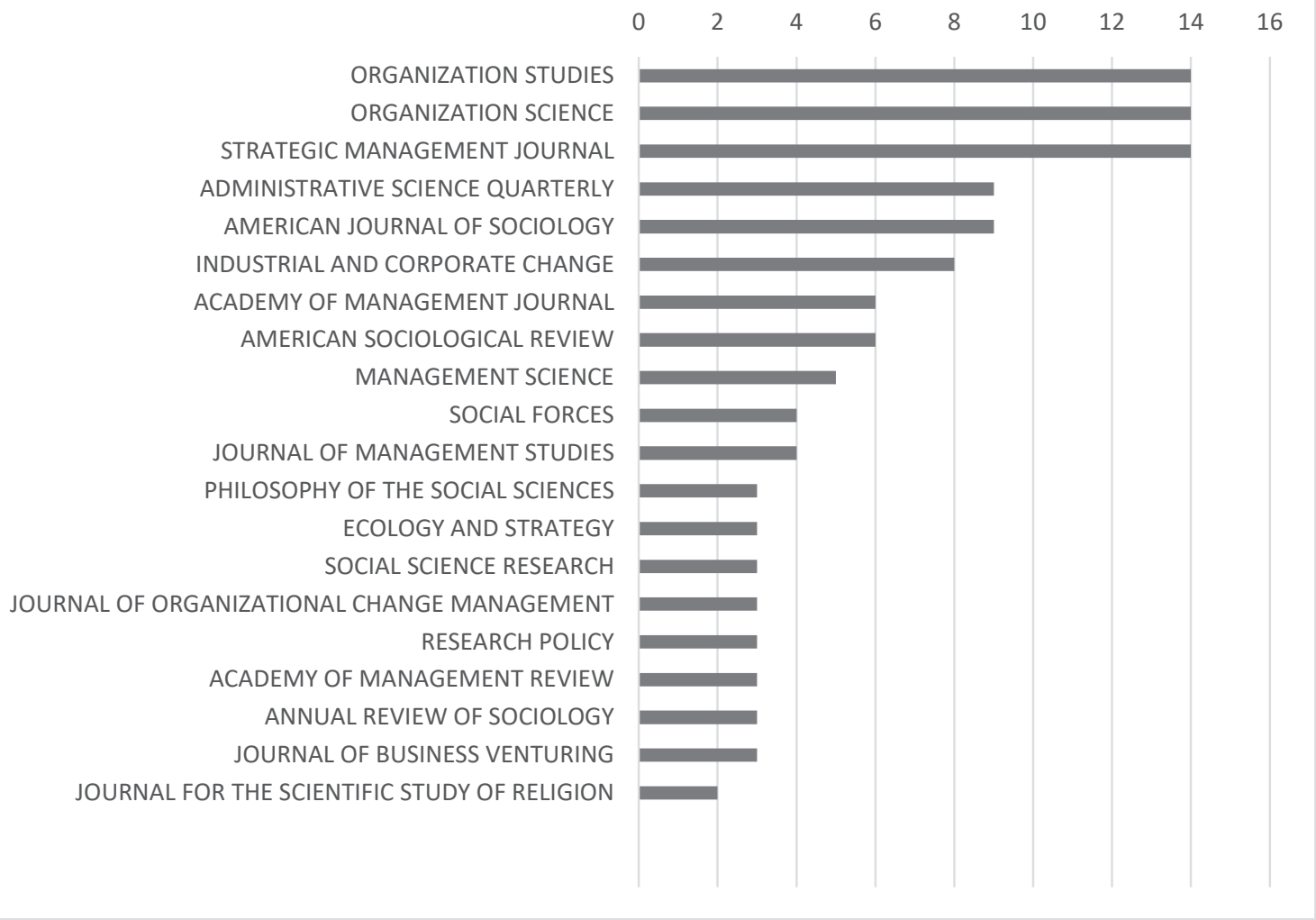

Fonte: elaborado pelos autores, gerado por Bibliometrix R Studio.

Em geral, os periódicos relacionados estão intimamente ligados às ciências sociais, por ser um tema de estudo de abrangência social. Além disso, os dados explicitam que os autores dos estudos estão concentrados em instituições de renome internacional, como Stanford University, University of California, University of Toronto e University of Groningen.

Em relação ao gráfico 6, observam-se os países mais citados nos estudos sobre Ecologia Organizacional. O maior destaque é os Estados Unidos, seguido pelo Canadá, Países Baixos, Alemanha e Reino Unido, em consonância com estudos anteriores (HOLGADO-SILVA et al., 2018). Os demais países apresentam baixa relevância nas discussões sobre o tema, inclusive, o Brasil. O estudo Towards a semiotic theory of the Corporation (BAU MACEDO; HERRMANN-PILLA$\mathrm{TH}, 2019)$ consta como um dos poucos com participação nacional. 
Gráfico 6 - Países mais citados nos estudos das bases Web of Science

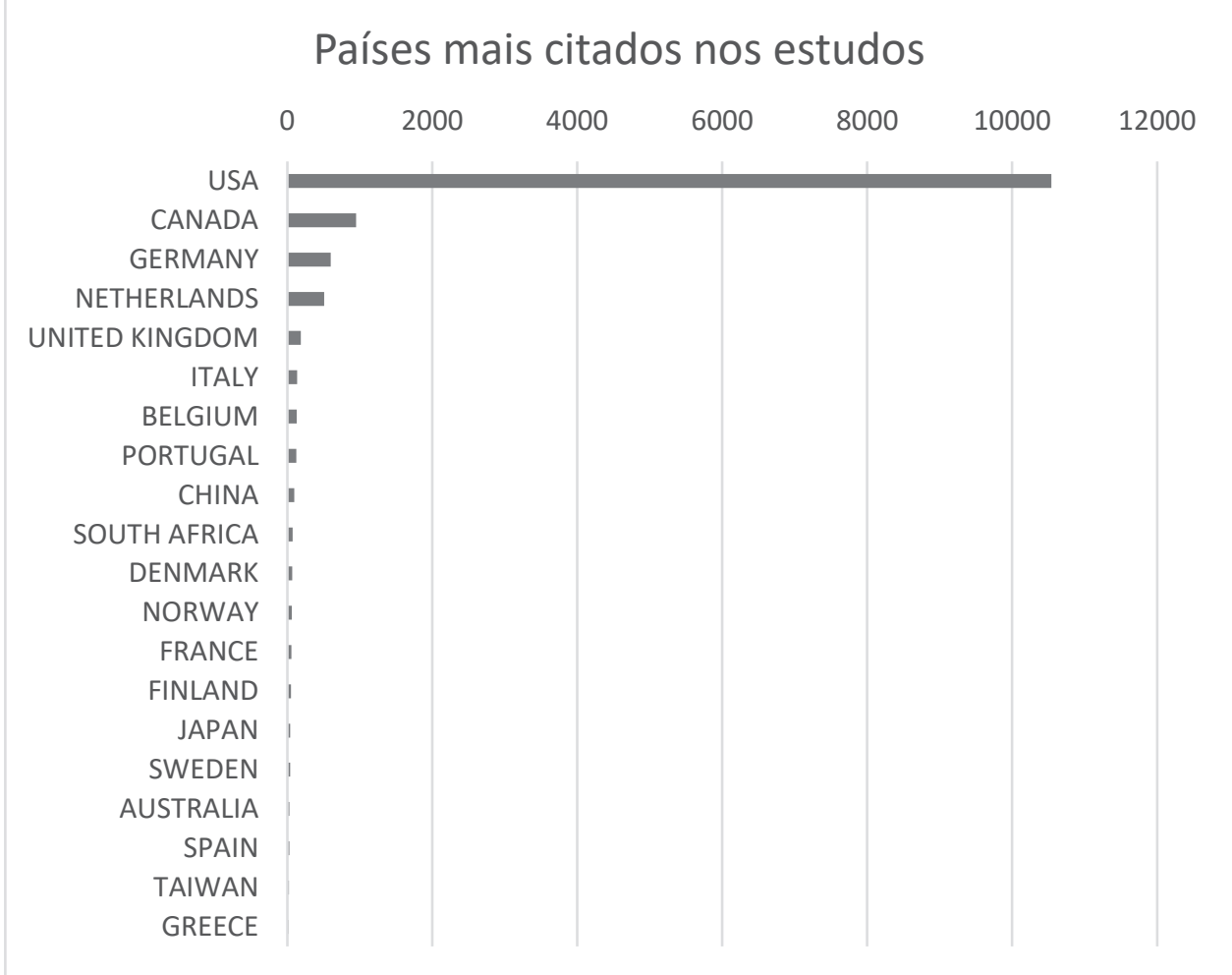

Fonte: elaborado pelos autores, gerado por Bibliometrix R Studio.

A figura 1 possibilita uma análise mais detalhada do rumo dado aos estudos com a temática em questão. Inicialmente, a coluna à esquerda apresenta os autores mais referenciados quando se observam os estudos publicados. É nítido que a literatura clássica do tema se destaca nas duas bases, com os estudos de Hannan e Freeman $(1977,1984)$. Além disso, o estudo de Carroll e Hannan (2000) é o de menor idade apontado nas referências.

Ainda na figura 1, a coluna intermediária refere-se aos países de origem dos estudos, confirmando o predomínio norte-americano, como já descrito anteriormente. A coluna à direita apresenta termos-chave com maior grau de importância. Observa-se o predomínio das terminologias básicas envolvendo a teoria em questão. Em menor número, vale destacar termos como "China", "Korea" e "Japan", em que os Estados Unidos aparecem como ligação. Isso se deve ao surgimento de estudos comparando algum fenômeno organizacional entre esses países, como a constatação de que o aprendizado organizacional modera os efeitos da distância institucional no setor internacional de serviços (DIKOVA; SAHIB; VAN WITTELOOSTUIJN, 2010). Essa análise além das fronteiras é uma característica importante em face das condições de internacionalização abordadas pela teoria da Ecologia Organizacional. 
Figura 1 - Análise de três campos das bases Scopus e Web of Science

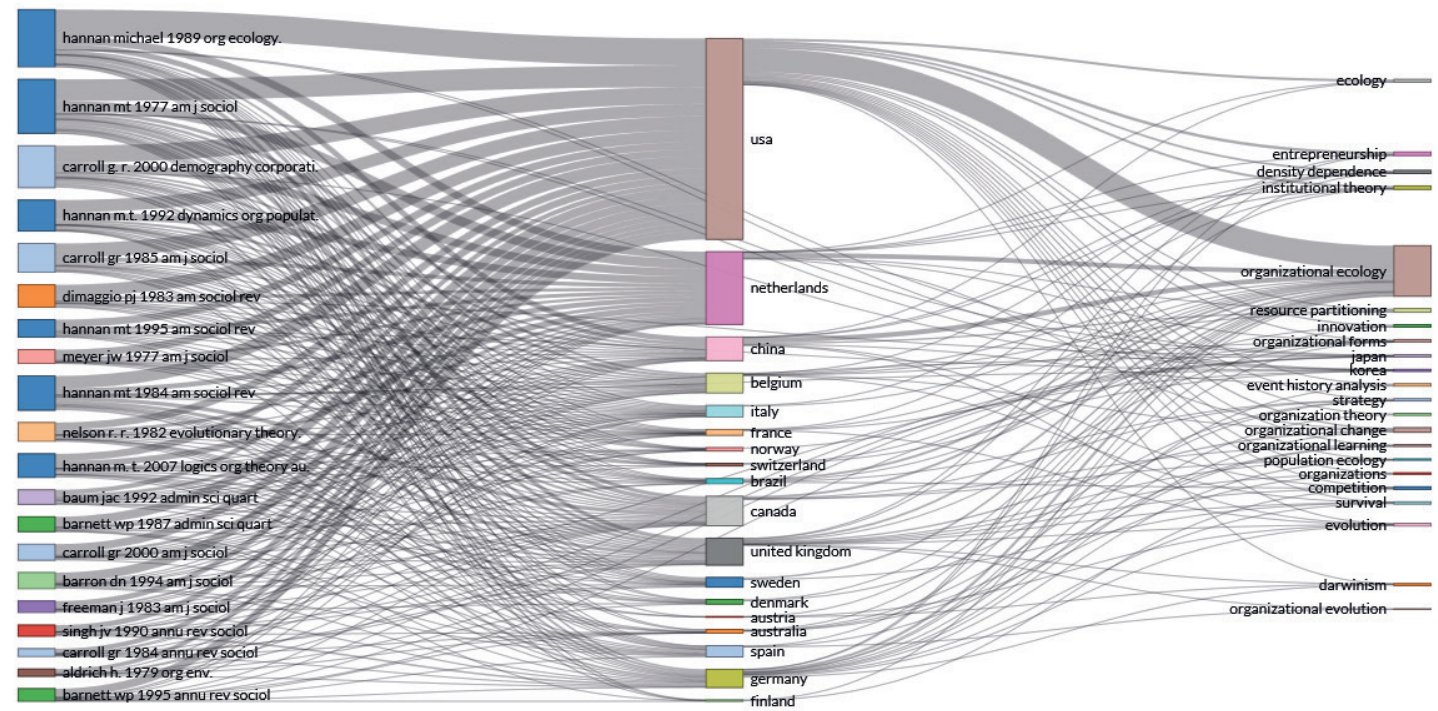

Nota: A coluna à esquerda representa os autores mais referenciados na amostra. A coluna do meio representa os países de origem dos artigos da amostra. A coluna à direita representa as palavras-chave mais utilizadas na amostra.

Fonte: elaborada pelos autores, gerado por Bibliometrix R Studio.

Observa-se, também, o termo "entrepreunership" que ainda é pouco explorado, apesar de sua importância econômica. Uma aplicação sistemática de modelos ecológicos ao empreendedorismo revela lacunas significativas, sendo necessárias pesquisas e modelagens adicionais (ALDRICH; WIEDENMAYER, 2019). O termo "event analysis history" aparece como metodologia de comprovação dos pressupostos teóricos, já que análises de longo prazo podem evidenciar mudanças estruturais e estratégicas da organização. Um termo recorrente na literatura da teoria é nicho, que não aparece nas bases analisadas, sugerindo um assunto importante a ser explorado pela perspectiva da Ecologia Organizacional.

Dessa forma, foi possível identificar o panorama atual da literatura sobre Ecologia Organizacional, no âmbito mundial. Foi evidenciado que os países economicamente desenvolvidos (Estados Unidos, Canadá, Países Baixos, Alemanha e Reino Unido) possuem maior interesse pela temática e, consequentemente, maior contribuição. Análises comparativas com os tigres asiáticos (Japão, Coréia e
China) surgem como ampliação dos estudos norte-americanos.

Ainda que timidamente, o Brasil é apontado em citações, indicando uma mudança na forma de enxergar as teorias organizacionais. Isso não significa ausência de estudos brasileiros (CUNHA, 1999; GUERRAZZI; SERRA, 2017; HOLGADO-SILVA et al., 2018; MEIRELLES E SILVA; THOMAZ, 2016; SILVA; SANTOS; MACEDO, 2019), mas de análises qualificadas e de impacto internacional (HOLGADO-SILVA et al., 2018). Assim, é necessário explorar o assunto fora dos grandes eixos e além dos pressupostos básicos.

Ao identificar similaridade de perfil entre os estudos das bases Scopus e Web of Science, foi possível enumerar os estudos mais referenciados nas pesquisas abordando o tema (tabela 2). Os estudos pioneiros de Hannan e Freeman, e, em seguida, os estudos de Carroll são as principais referências, destacando a relevância do campo teórico para o aprimoramento de novas pesquisas. Nesse sentido, uma quantidade restrita de autores compõe a base de conhecimento para a Teoria da Ecologia organizacional. 
Tabela 2 - Estudos mais referenciados nas pesquisas entre a base Scopus e Web of Science

\begin{tabular}{|c|c|}
\hline Ordem & Estudo mais referenciado nas pesquisas \\
\hline 1 & $\begin{array}{l}\text { Hannan, M. T., \& John Freeman. (1977). The Population Ecology of Organizations. American } \\
\text { Journal of Sociology, 82(5), 929-964. https://doi.org/10.1086/226424 }\end{array}$ \\
\hline 2 & $\begin{array}{l}\text { Hannan, M. T., \& Freeman, J. (1989). Organizational Ecology. Cambridge: Harvard University } \\
\text { Press. Retrieved from https://books.google.com.br/books?id=UVHDye2683gC }\end{array}$ \\
\hline 3 & $\begin{array}{l}\text { Hannan, M. T., \& Freeman, J. (1984). Structural Inertia and Organizational Change Author ( } \\
\text { s ): Michael T . Hannan and John Freeman Source: American Sociological Review, Vol . } 49 \\
\text {, No . } 2 \text { ( Apr ., } 1984 \text { ), pp . 149-164 Published by: American Sociological Association Stable } \\
\text { URL: http://www. American Sociological Review, } 49(2), 16 .\end{array}$ \\
\hline 4 & $\begin{array}{l}\text { Carroll, G. R. (1985). Concentration and specialization: dynamics of niche width in popu- } \\
\text { lations of organizations. American Journal of Sociology, 90(6), 1262-1283. https://doi. } \\
\text { org/10.1086/228210 }\end{array}$ \\
\hline 5 & $\begin{array}{l}\text { Singh, J. V, \& Lumsden, C. J. (1990). Theory and Research in Organizational Ecology. Annual } \\
\text { Review of Sociology, 16(1), 161-195. https://doi.org/10.1146/annurev.so.16.080190.001113 }\end{array}$ \\
\hline 6 & $\begin{array}{l}\text { DiMaggio, P., \& Powell, W. (1983). The Iron Cage Revisited: Institutional Isomorphism in } \\
\text { Organizational Fields. American Sociological Review, } 48(2), 147-160 .\end{array}$ \\
\hline 7 & $\begin{array}{l}\text { Carroll, G. R. (1984). Organizational ecology. Annual Review of Sociology. Vol. 10, (1977), } \\
\text { 71-93. https://doi.org/10.4135/9781446218556.n3 }\end{array}$ \\
\hline
\end{tabular}

$8 \quad$ Carroll, Glenn R., \& Hannan, M. T. (2000). The Demography of Corporations and Industries. The Demography of Corporations and Industries (Vol. 29). Princeton: Princeton University Press. https://doi.org/10.1515/9780691186795

9 Barron, D. N., West, E., \& Hannan, M. T. (1994). A Time to Grow and a Time to Die: Growth and Mortality of Credit Unions in New York City, 1914-1990. American Journal of Sociology, 100(2), 381-421. https://doi.org/10.1086/230541

10 Meyer, J. W., \& Rowan, B. (1977). Institutionalized Organizations: Formal Structure as Myth and Ceremony. American Journal of Sociology, 83(2), 340-363. https://doi.org/10.1086/226550

11 Barnett, W. P., \& Carroll, G. R. (1987). Competition and Mutualism among Early Telephone Companies. Administrative Science Quarterly, 32(3), 400-421.

12 Freeman, J., \& Hannan, M. T. (1983). Niche width and the dynamics of organizational populations. American Journal of Sociology, 88(6), 1116-1145. https://doi.org/10.1086/227797

13 Carroll, Glenn R., \& Hannan, M. T. (1989). Density Dependence in the Evolution of Populations of Newspaper Organizations. American Sociological Review, 54(4), 524. https://doi. org $/ 10.2307 / 2095875$

14 Barnett, W. P., \& Carroll, G. R. (1995). Modeling Internal Organizational Change. Annual Review of Sociology, 21(1), 217-236. https://doi.org/10.1146/annurev.so.21.080195.001245

Fonte: elaborado pelos autores, gerado por Bibliometrix R Studio.

Os artigos refletem ampla qualidade nas contribuições teóricas e empíricas para a análise dos pressupostos da ecologia organizacional. Entretanto, é possível argumentar muito sobre sua robustez, já que organizações e ambientes mudam continuamente. Análises estáticas podem não refletir a evolução do mundo organizacional (CARROLL, 2004), o que exige pesquisas e análises contínuas sobre a maneira como os recursos e a performance institucional se desenvolvem ao longo do tempo no ambiente. Por ser uma resposta aos desafios ambientais em conjunto com a dinâmica organizacional, o desempenho das organizações não é estacionário (BARNETT; GREVE; PARK, 1994) diante do papel do tempo na evolução organizacional, assim como o campo teórico. 


\section{CONSIDERAÇÕES FINAIS}

Como as organizações interagem em um ambiente incerto, seus esforços adaptativos são fundamentais para sobrevivência e perpetuação. Ao mesmo tempo, entender essas metamorfoses pode elevar a capacidade de acertos futuros. Por isso, este estudo objetivou delinear o panorama atual da produção científica nacional e internacional relacionada à perspectiva da Ecologia Organizacional. Para tanto, realizou-se uma pesquisa bibliométrica por meio da base de dados Web of Science e Scopus, que resultou em 604 artigos pelo período entre 1958 e 2020 .

Quanto às perspectivas envolvendo a academia, os interesses e focos de investigação apresentaram relevante crescimento e destaque dessa teoria para o conhecimento científico. Com isso, o mapeamento da produção apontou um cenário amplamente relacionado aos países economicamente desenvolvidos (Estados Unidos, Canadá, Países Baixos, Alemanha e Reino Unido). Ao mesmo tempo, países como o Brasil não possuem destaque em pesquisas sobre o tema, explicitando novas oportunidades no âmbito acadêmico.

Em relação às temáticas, verificou-se uma representatividade em publicações apontando diversas perspectivas e fenômenos de interesse da Ecologia Organizacional, apesar de uma concentração no tema geral. Os autores que mais publicaram nesse tema também tiveram seus trabalhos reconhecidos com maior número de citações, como Glenn R. Carroll e Arjen Van Witteloostuijn. As instituições que se destacaram são Stanford University, University of California, University of Toronto e University of Groningen.

A contribuição deste estudo é tripla. Primeiro, conectamos as literaturas relacionadas à ecologia organizacional de relevância tanto nacional como internacional. Segundo, fornecemos uma visão quantitati- va da evolução da temática desde seu surgimento na literatura cujos indicadores resultantes apontam instituições, estudiosos e periódicos relevantes que aparecem na produção do conhecimento. Terceiro, fica evidenciado o potencial dessa teoria para fundamentar investigações diante das diretrizes fornecidas pela teoria, possibilitando, na prática, intervenções organizacionais como respostas planejadas às mudanças ambientais. Isso permite uma visão geral rápida, mas abrangente das principais relações dentro do campo e constitui uma base sólida para revisões qualitativas complementares de subcampos mais restritos da pesquisa. Apesar disso, os resultados demonstram que as análises de destaque nacional ainda apresentam baixa representatividade em relação ao nível internacional.-

Os resultados aqui apresentados têm limitações quanto à análise de alguns indexadores, devido à incompatibilidade de outras bases com as ferramentas tecnológicas para análise bibliométrica. Nesse sentido, sugere-se ampliar o estudo da temática em outras bases como também em eventos científicos relacionados ao tema. Além disso, abordar o fator de impacto pode trazer novas perspectivas sobre a utilização da teoria subsidiando outros campos da pesquisa, bem como a contribuição desses estudos na evolução científica. Por fim, os resultados apontam, também, lacunas que poderiam ser preenchidas em futuras pesquisas, como pesquisas sobre startups no Brasil à luz das premissas da ecologia organizacional podem apontar fatores explicativos, para a sua emergência e fracasso, ainda não encontrados. Questões estratégicas organizacionais também podem ser analisadas nesse contexto, abrangendo, por exemplo, as condições de diferencial competitivo. 


\section{REFERÊNCIAS}

ABBOTT, Kenneth W.; GREEN, Jessica F.; KEOHANE, Robert O. Organizational Ecology and Institutional Change in Global Governance. International Organization, v. 70, n. 2, p. 247-277, 2016. DOI: 10.1017/ S0020818315000338.

AL-TURK, Akram; ALDRICH, Howard E. Revisiting "Traits To Rates" After 25 Years: Organizational Ecology's Limited Impact on Entrepreneurship Research. In: KATZ, J. A.; CORBET, A. C. (org.). Advances in Entrepreneurship, Firm Emergence and Growth. Bingley: Emerald Publishing Limited, 2019. v. 21. p. 99-114. DOI: 10.1108/S1074754020190000021004 .

ALDRICH, Howard E.; WIEDENMAYER, Gabriele. From Traits to Rates: An Ecological Perspective on Organizational Foundings. In: KATZ, J. A.; CORBET, A. C. (org.). Advances in Entrepreneurship, Firm Emergence and Growth. Bingley: Emerald Publishing Limited, 2019. v. 21. p. 61-97. DOI: 10.1108/S1074754020190000021010 .

ARCHAMBAULT, Éric et al. Comparing bibliometric statistics obtained from the Web of Science and Scopus. Journal of the American Society for Information Science and Technology, v. 60 , n. 7, p. 1320-1326, 2009. DOI: 10.1002/asi.21062.

BARNETT, William P.; CARROLL, Glenn R. Competition and Mutualism among Early Telephone Companies. Administrative Science Quarterly, v. 32, n. 3, p. 400-421, 1987.

BARNETT, William P.; GREVE, Henrich R.; PARK, Douglas Y. An Evolutionary Model of Organizational Performance. Strategic Management Journal, v. 15, n. 1, S, p. 11-28, 1994. DOI: $10.1002 / \mathrm{smj} .4250150903$.

BAUM, Joel A. C.; MEZIAS, Stephen J. Localized Competition and Organizational Failure in the Manhattan Hotel Industry, 1898-1990. Ad- ministrative Science Quarterly, v. 37, n. 4, p. 580, 1992. DOI: $10.2307 / 2393473$.

BECK, Nikolaus et al. Industry Clusters and Organizational Prototypes: Evidence From the Franconian Brewing Industry. Journal of Management, v. 45, n. 7, p. 2978-3008, 2019. DOI: $10.1177 / 0149206318773411$.

BIENERT, Igor R. C. et al. Bibliometric indexes, databases and impact factors in cardiology. Revista Brasileira de Cirurgia Cardiovascular, v. 30 , n. 2 , p. $254-259$, 2015. DOI: 10.5935/1678-9741.20150019.

BOAVIDA, Clara; RODRIGUES, Eloy; SARAIVA, Ricardo. Produção científica da Universidade do Minho indexada na Web of Science e ScopusUniversidade do Minho. Braga. [S.l.: s.n.], 2015.

ÇAKMAKLI, Anıl Divarc1; BOONE, Christophe; VAN WITTELOOSTUIJN, Arjen. Identity realization, multiple logics and legitimacy: Organizational foundings during the emergence of the Dutch accounting industry. Accounting, Organizations and Society, v. 83, p. 101104, 2020. DOI: 10.1016/j. aos.2020.101104.

CARROLL. Organizational ecology. Annual review of sociology. Vol. 10, , n. 1977, p. 7193, 1984. DOI: 10.4135/9781446218556.n3.

CARROLL. Concentration and Specialization: Dynamics of Niche Width in Populations of Organizations. American Journal of Sociology, v. 90, n. 6, p. 1262-1283, 1985. DOI: $10.1086 / 228210$.

CARROLL; DOBREV, Stanislav D.; SWAMINATHAN, Anand. Organizational processes of resource partitioning. Research in Organizational Behavior, v. 24, p. 1-40, 2002. DOI: 10.1016/S0191-3085(02)24002-2.

CARROLL, G. R. Organizational ecology: an introduction. Industrial and Corporate Change, v. 13, n. 1, p. 1-1, 2004. DOI: 10.1093/icc/13.1.1. 
CARROLL; SWAMINATHAN, Anand. Why the microbrewery movement? Organizational dynamics of resource partitioning in the US brewing industry. The Competitive Dynamics of Entrepreneurial Market Entry, v. 106, n. 3, p. 127-175, 2011.

CLEGG, Stewart. American anti-management theories of organization: A critique of paradigm proliferation. Australian Journal of Management, v. 21, n. 2, p. 189-193, 1996. DOI: $10.1177 / 031289629602100205$.

CLEMENTS, Hayley S.; BAUM, Julia; CUMMING, Graeme S. Money and motives: An organizational ecology perspective on private land conservation. Biological Conservation, v. 197 , p. 108-115, 2016. DOI: 10.1016/j.biocon.2016.03.002.

CUNHA, Miguel Pina e. Ecologia organizacional: implicações para a gestão e algumas pistas para a superação de seu caráter anti-management. Revista de Administração de Empresas, v. 39 , n. 4, p. 21-28, 1999. DOI: $10.1590 /$ s0034-75901999000400003.

DAIM, Tugrul U. et al. Forecasting the future of data storage: Case of hard disk drive and flash memory. Foresight, v. 10, n. 5, p. 34-49, 2008. DOI: $10.1108 / 14636680810918496$.

DELMAR, Frédéric; SHANE, Scott. Legitimating first: Organizing activities and the survival of new ventures. Journal of Business Venturing, v. 19, n. 3, p. 385-410, 2004. DOI: 10.1016/S0883-9026(03)00037-5.

DENIS, Gil et al. From new space to big space: how commercial space dream is becoming a reality. Acta Astronautica, v. 166, p. 431-443, 2020. DOI: 10.1016/j.actaastro.2019.08.031.

DIKOVA, Desislava; SAHIB, Padma Rao; VAN WITTELOOSTUIJN, Arjen. Cross-border acquisition abandonment and completion: The effect of institutional differences and organizational learning in the international business service industry, 1981-2001. Journal of International Business Studies, v. 41, n. 2, p.
223-245, 2010. DOI: 10.1057/jibs.2009.10.

DIMAGGIO, Paul; POWELL, Walter. The Iron Cage Revisited: Institutional Isomorphism in Organizational Fields. American Sociological Review, v. 48, n. 2, p. 147-160, 1983.

DOUGALL, Elizabeth. Revelations of an ecological perspective: Issues, inertia, and the public opinion environment of organizational populations. Public Relations Review, v. 31, n. 4, p. 534-543, 2005. DOI: 10.1016/j. pubrev.2005.08.013.

FREEMAN, John; HANNAN, Michael T. Niche width and the dynamics of organizational populations. American Journal of Sociology, v. 88 , n. 6 , p. 1116-1145, 1983. DOI: 10.1086/227797.

FREEMAN, John; HANNAN, Michael T. Commentary and Debate. American Journal of Sociology, v. 95, n. 2, p. 425-439, 2014.

FREITAS, Maria Ester. Reseña de "Handbook de Estudos Organizacionais. Modelos de Análise e Novas Questôes em Estudos Organizacionais". Revista de Administração de Empresas, v. 40, n. 1, p. 105-107, 2000.

GANG, Kwang Wook. The impact of pre-entry experiences on entry decisions and firm survival. Technological Forecasting and Social Change, v. 137, p. 249-258, 2018. DOI: 10.1016/j.techfore.2018.07.058.

GIBBS, Jack P.; MARTIN, Walter T. Urbanization and Natural Resources: A Study in Organizational Ecology. American Sociological Review, v. 23, n. 3, p. 266-277, 1958. DOI: $10.2307 / 2089240$.

GREVE, Henrich R.; ARGOTE, Linda. Behavioral Theories of Organization. Second Edi ed. [S.l.]: Elsevier, 2015. v. 2 DOI: 10.1016/ B978-0-08-097086-8.73121-7.

GUERRAZZI, Luiz Antonio de Camargo; SERRA, Fernando Antonio Ribeiro. Declínio em pequenas empresas: abordagens e traba- 
lhos relevantes. REAd. Revista Eletrônica de Administração (Porto Alegre), v. 23, n. 3, p. 206-238, 2017. DOI: 10.1590/14132311.176 .66629 .

HANNAN, Michael T. et al. Organizational evolution in a multinational context: entries of automobile manufacturers in Belgium, Britain, France, Germany, and Italy. American Sociological Review, v. 60, n. 4, p. 509-528, 1995. DOI: $10.2307 / 2096291$.

HANNAN, Michael T.; FREEMAN, John. The Population Ecology of Organizations. American Journal of Sociology, v. 82, n. 5, p. 929964, 1977. DOI: $10.1086 / 226424$.

HANNAN, Michael T.; FREEMAN, John. Structural Inertia and Organizational Change. American Sociological Review, v . 49 , n. 2, p . 149-164, 1984.

HATCH, Mary Jo; CUNLIFFE, Ann L. Organization theory: modern, symbolic, and postmodern perspectives. 30. ed. Oxford: Oxford University Press, 2006. v. 53. DOI: 10.1017/ CBO9781107415324.004.

HAVEMAN, Heather A.; WETTS, Rachel. Contemporary organizational theory: The demographic, relational, and cultural perspectives. Sociology Compass, v. 13, n. 3, p. 1-20, 2019. DOI: $10.1111 /$ soc4.12664.

HOLGADO-SILVA, Heloiza Cristina et al. Bibliometria em estudos organizacionais: o perfil das produções em ecologia das organizações. Gestão e Sociedade, v. 12 , n. 31 , p. 2042 2066, 2018. DOI: 10.21171/ges.v12i31.2297.

HSU, Greta; HANNAN, Michael T. Identities, genres, and organizational forms. Organization Science, v. 16, n. 5, p. 474-490, 2005. DOI: 10.1287 /orsc.1050.0151.

HSU, Greta; KOVÁCS, Balázs; KOÇAK, Özgecan. Experientially diverse customers and organizational adaptation in changing demand landscapes: A study of US cannabis markets, 2014-2016. Strategic Management Journal, v. 40, n. 13 , p. $2214-2241,2019$. DOI: $10.1002 /$ smj.3078.

KAUFMANN, Wesley; VAN WITTELOOSTUIJN, Arjen. Do Rules Breed Rules? Vertical Rule-Making Cascades at the Supranational, National, and Organizational Level. International Public Management Journal, v. 21, n. 4, p. 650-676, 2018. DOI: 10.1080/10967494.2016.1143420.

KÜCHER, Alexander; FELDBAUER-DURSTMÜLLER, Birgit. Organizational failure and decline - A bibliometric study of the scientific frontend. Journal of Business Research, v. 98, p. 503-516, 2019. DOI: 10.1016/j.jbusres.2018.05.017.

KÜCHER, Alexander et al. Birgit. Firm age dynamics and causes of corporate bankruptcy: age dependent explanations for business failure. Review of Managerial Science, v. 14, n. 3, p. 633-661, 2020. DOI: $10.1007 / \mathrm{s} 11846-$ 018-0303-2.

LANDER, Michel W.; HEUGENS, Pursey P. M. A. R. Better Together: Using Meta-Analysis to Explore Complementarities between Ecological and Institutional Theories of Organization. Organization Studies, v. 38, n. 11, p. 15731601, 2017. DOI: 10.1177/0170840616677629.

LE MENS, Gaël; HANNAN, Michael T.; PÓLOS, László. Age-Related Structural Inertia: A Distance-Based Approach. Organization Science, v. 26, n. 3, p. 756-773, 2015. DOI: $10.1287 /$ orsc. 2015.0966 .

LJUBOWNIKOW, Grigorij; ANG, Siah Hwee. Competition, diversification and performance. Journal of Business Research, v. 112, n. 1959, p. 81-94, 2020. DOI: 10.1016/j.jbusres.2020.03.002.

MACEDO, Luís Otávio Bau; HERRMANN-PILLATH, Carsten. Towards a semiotic theory of the corporation. Social Semiotics, v. 42, n. 3, p. 1-23, 2019. DOI: 10.1080/10350330.2019.1629530. 
MAKAREVICH, Alex. Ties of survival: Specialization, inter-firm ties, and firm failure in the U.S. venture capital industry. Journal of Business Research, v. 86, p. 153-165, 2018. DOI: 10.1016/j.jbusres.2018.02.001.

MARQUESAN, Fábio Freitas Schilling; FIGUEIREDO, Marina Dantas De. Do ecoambientalismo à sustentabilidade: notas críticas sobre a relação organização-natureza nos estudos organizacionais. Organizações \& Sociedade, v. 25 , n. 85 , p. 264-286, 2018. DOI: 10.1590/1984-9250855.

MEIRELLES E SILVA, Dimaria; THOMAZ, José Carlos. Sobrevivência Organizacional Das Administradoras De Consórcio No Brasil: Uma Abordagem Evolucionária. Revista Alcance, v. 23 , n. 2, p. 170, 2016. DOI: 10.14210/alcance.v23n2.p170-188.

MENDOZA-ABARCA, Karla I.; ANOKHIN, Sergey; ZAMUDIO, César. Uncovering the influence of social venture creation on commercial venture creation: A population ecology perspective. Journal of Business Venturing, v. 30 , n. 6 , p. $793-807,2015$. DOI: $10.1016 / j$. jbusvent.2015.04.003.

MEYER, John W.; ROWAN, Brian. Institutionalized Organizations: Formal Structure as Myth and Ceremony. American Journal of Sociology, v. 83, n. 2, p. 340-363, 1977. DOI: $10.1086 / 226550$.

MORIN, Jean-Frédéric. Concentration despite competition: The organizational ecology of technical assistance providers. The Review of International Organizations, v. 15, n. 1, p. 75-107, 2020. DOI: 10.1007/s11558-0189322-7.

OVERLAND, Indra; REISCHL, Gunilla. A place in the Sun? IRENA's position in the global energy governance landscape. International Environmental Agreements: Politics, Law and Economics, v. 18, n. 3, p. 335-350, 2018. DOI: $10.1007 / \mathrm{s} 10784-018-9388-y$.
PENG, George Z.; BEAMISH, Paul W. Subnational FDI Legitimacy and Foreign Subsidiary Survival. Journal of International Management, v. 25, n. 3, p. 100662, 2019. DOI: 10.1016/j.intman.2018.12.003.

POSTHUMA, Richard A. et al. Social signaling and interorganizational relationships: Lessons learned from the professional sports industry. Business Horizons, v. 61, n. 4, p. 521-531, 2018. DOI: 10.1016/j.bushor.2018.03.001.

POWERS, Angela; ZHAO, Jingyan. Staying alive: entrepreneurship in family-owned media across generations. Baltic Journal of Management, v. 14 , n. 4, p. 641-657, 2019. DOI: 10.1108/BJM-01-2018-0033.

RATINHO, Tiago et al. Supporting entrepreneurs: A systematic review of literature and an agenda for research. Technological Forecasting and Social Change, v. 154, p. 119956, 2020. DOI: 10.1016/j.techfore.2020.119956.

REN, Hao et al. How Do Internet Enterprises Obtain Sustainable Development of Organizational Ecology? A Case Study of LeEco Using Institutional Logic Theory. Sustainability, v. 9, n. 8 , p. 1375,2017 . DOI: 10.3390/su9081375.

SILVA, Luciano Ferreira Da; FIGUEIREDO, Jocely Santos; SANTOS, Bruno Quintiliano Dos. O ecossistema das bancas de jornal: um estudo sobre uma espécie em extinção. Revista Eletrônica em Gestão, Educação e Tecnologia Ambiental, v. 19, n. 1, p. 80-95, 2015. DOI: $10.5902 / 2236117015533$.

SILVA, Mara Rosalia Ribeiro; SANTOS, Ana Sara Leite; MACEDO, Augusto Cezar Moura De. Inovação, Sobrevivência e Ecologia Organizacional: Possibilidades de Relação. Revista Administração em Diálogo - RAD, v. 21, n. 2, p. $148-163$, 2019. DOI: $10.23925 / 2178-$ $0080.2019 \mathrm{v} 21 \mathrm{i} 2.39164$.

SINGH, Riann; RAMDEO, Shalini. Organizational-Level Theories. In: LEADING Organizational Development and Change. Cham: Springer International Publishing, 2020. p. 247-260. 
DOI: 10.1007/978-3-030-39123-2_11.

SINGH, Jitendra V.; LUMSDEN, Charles J. Theory and Research in Organizational Ecology. Annual Review of Sociology, v. 16, n. 1, p. 161-195, 1990. DOI: 10.1146/annurev. so.16.080190.001113.

SOUZA, Cláudia Daniele De. A organização do conhecimento: Estudo bibliométrico na base de dados ISI Web of Knowledge. Biblios: Journal of Librarianship and Information Science, v. 51, n. 51, p. 20-32, 2013. DOI: 10.5195/biblios.2013.108.

SWAMINATHAN, Anand; WIEDENMAYER, Gabriele. Does the pattern of density dependence in organizational mortality rates vary across levels of analysis? evidence from the German brewing industry. Social Science Research, v. 20, n. 1, p. 45-73, 1991. DOI: 10.1016/0049-089X(91)90003-L.

TREMBLAY, Victor J. The organizational ecology of strategic groups in the American brewing industry: A comment. Industrial and Corporate Change, v. 2, n. 1, p. 91-98, 1993. DOI: 10.1093/icc/2.1.91.

TSAI, William Ming Hone; MACMILLAN, Ian C.; LOW, Murray B. Effects of strategy and environment on corporate venture success in industrial markets. Journal of Business Venturing, v. 6, n. 1, p. 9-28, 1991. DOI: 10.1016/0883-9026(91)90003-V.

VAN WITTELOOSTUIJN, Arjen et al. Explaining the survival of public organizations: Applying density dependence theory to a population of US federal agencies. Public Administration, v. 96, n. 4, p. 633-650, 2018. DOI: $10.1111 /$ padm. 12524 .

VERHAAL, J. Cameron; KHESSINA, Olga M.; DOBREV, Stanislav D. Oppositional product names, organizational identities, and product appeal. Organization Science, v. 26 , n. 5 , p. $1466-1484,2015$. DOI: $10.1287 /$ orsc. 2015.1000 .
WALLIN, Johan A. Bibliometric Methods: Pitfalls and Possibilities. Basic \& Clinical Pharmacology \& Toxicology, v. 97, n. 5, p. 261275, 2005. DOI: 10.1111/j.1742-7843.2005. pto_139.x. 